\title{
Hemoglobin measured by Hemocue and a reference method in venous and capillary blood: A validation study
}

\author{
Lynnette N eufeld, PhD, MSc, BA Sc, ${ }^{(1)}$ Armando García-Guerra, M en $C_{,}{ }^{(1)}$ \\ D omingo Sánchez-Francia, Q FB, ${ }^{(2)} 0$ scar N ewton-Sánchez, MC, ${ }^{(2)}$ María D olores Ramírez-Villalobos, MC, ${ }^{(3)}$ \\ Juan Rivera-D ommarco, M Sc, PhD.11
}

Neufeld L, García-Guerra A, Sánchez-Francia D,
Newton-Sánchez O, Ramírez-Villalobos MD,
Rivera-Dommarco J.
Hemoglobin measured by Hemocue
and a reference method in venous
and capillary blood:A validation study.
Salud Publica Mex 2002;44:219-227. http://www.insp.mx/salud/index.html

\begin{abstract}
A bstract
Objective To assess the comparability of hemoglobin concentration $(\mathrm{Hb})$ in venous and capillary blood measured by Hemocue and an automated spectrophotometer (C elldyn) and to document the influence of type of blood (capillary or venous) and analysis method on anemia prevalence estimates. Material and Methods Between February and May 2000, capillary and venous samples were collected from 72 adults and children at Hospital del $\mathrm{N}$ iño Morelense (Morelos State Children's Hospital) in C uernavaca, Morelos, Mexico, and assessed for $\mathrm{Hb}$ using the Hemocue and Celldyn methods. Estimated $\mathrm{Hb}$ levels were compared using the concordance correlation coefficient and Student's t test for paired data. The sensitivity and specificity for anemia diagnosis were estimated and compared between type of blood and method of assessment. Results. Capillary blood had higher $\mathrm{Hb}(+0.5 \mathrm{~g} / \mathrm{dl})$ than venous blood in adults and children, as did samples assessed by Celldyn compared to Hemocue $(+0.3 \mathrm{~g} / \mathrm{dl})$. Specificity to detect anemia was adequate $(>0.90)$ but sensitivity was low for capillary blood assessed by Hemocue $(<0.80)$. Conclusions. The difference in $\mathrm{Hb}$ between venous and capillary blood is likely related to biological variability. Hemoglobin concentration in capillary blood assessed by Hemocue provides an adequate estimation of population anemia prevalence but may result in
\end{abstract}

\author{
Neufeld L, García-Guerra A, Sánchez-Francia D, \\ Newton-Sánchez O, Ramírez-Villalobos MD, \\ Rivera-Dommarco J. \\ Hemoglobina medida por Hemocue \\ y por un método de referencia en sangre venosa \\ y capilar: estudio de validación. \\ Salud Publica Mex 2002;44:219-227. \\ El texto completo en inglés de este artículo también \\ está disponible en: http://www.insp.mx/salud/index.html
}

\section{Resumen}

Objetivo. Evaluar la comparabilidad de la concentración de hemoglobina $(\mathrm{Hb})$ en sangre venosa y capilar medida por Hemocue y por espectrofotómetro automatizado (C elldyn), así como documentar la influencia del tipo de sangre (capilar o venosa) y del método de análisis sobre la prevalencia de anemia. Material y métodos. De febrero a mayo de 2000 , se recolectaron muestras de sangre capilar y venosa en 72 adultos y niños en el Hospital del N iño Morelense, Cuernavaca, Morelos, México. Se determinaron los niveles de $\mathrm{Hb}$ con los métodos Hemocue y Celldyn. Las cifras de $\mathrm{Hb}$ estimadas se compararon con el coeficiente de concordancia y la prueba pareada de t de Student.También se comparó la sensibilidad y especificidad para el diagnóstico de anemia, utilizando sangre de los dos tipos y métodos de análisis. Resultados La Hb fue mayor en sangre capilar comparada con sangre venosa ( $+0.5 \mathrm{~g} / \mathrm{dl})$ en adultos y niños, y en las deter minaciones por C elldyn comparadas con las de Hemocue $(+0.3 \mathrm{~g} / \mathrm{dl})$. La especificidad para el diagnóstico de anemia fue adecuada ( $>0.90$ ), mientras que la sensibilidad fue baja para las muestras capilares medidas por Hemocue $(<0.80)$. Conclusiones Es probable que la diferencia en la $\mathrm{Hb}$ entre sangre venosa y capilar refleje variabilidad biológica. La Hb en sangre capilar medida por Hemocue provee una estimación adecuada de la prevalen-

(1) Centro de Investigación en N utrición y Salud, Instituto N acional de Salud Pública (IN SP), Cuernavaca, Morelos, México

(2) Hospital del Niño Morelense, Cuernavaca, Morelos, México

(3) Centro de Investigación en Sistemas de Salud, IN SP

Received on: July 12,2001 • Accepted on: 0 ctober 19,2001

Address reprint requests to: Dra. Lynnette N eufeld. División de Epidemiología de la N utrición, Centro de Investigaciones en N utrición y Salud. Instituto N acional de Salud Pública. Av. Universidad 655, colonia Santa María A huacatitlán, 62508 Cuernavaca, Morelos, México.

E-mail: Ineufeld@ correo.insp.mx 
excess false negative diagnoses among individuals. The results of this study stress the importance of sample collection technique, particularly for children. Method of analysis and sampling site need to be taken into consideration in field studies. The English version of this paper is available too at: http://www.insp.mx/salud/index.html

Key words: hemoglobin; Hemocue; C elldyn; reference methods; capillary blood; venous blood; anemia prevalence; Mexico cia de anemia en poblaciones, pero podría resultar en un exceso de diagnósticos falsos negativos. Los resultados de este estudio ponen énfasis en la importancia de la técnica de recolección de la muestra, particularmente en niños. Los méto dos de análisis y tipos de muestra de sangre deben ser tomados en cuenta en estudios de campo. El texto completo en inglés de este artículo también está disponible en: http://www.insp.mx/salud/index.html

Palabras clave: hemoglobina; H emocue; C elldyn; méto dos de referencia; sangre capilar; sangre venosa; anemia; M éxico
A nemia resulting from iron deficiency and other causes is estimated to affect up to $40 \%$ of women and children ${ }^{1}$ and as many as $50 \%$ of pregnant women ${ }^{2}$ worldwide. The diagnosis of anemia based on hemoglobin concentration $(\mathrm{Hb})$ in venous or capillary blood is used at the population level to estimate the prevalence of anemia, allocate resources, and target intervention programs to vulnerable groups; at the individual level, it is used to screen for participation in programs and to evaluate response to interventions. ${ }^{3}$

Some evidence exists that, when adequate capillary sample collection technique is used, capillary blood has, on average, a higher $\mathrm{Hb}$ than venous blood in adults ${ }^{4,5}$ and children. ${ }^{6,7}$ If this is confirmed, a diagnosis of anemia based on $\mathrm{Hb}$ in capillary blood may be less likely for a given individual. Within a research project or within a single clinic, this difference can be controlled by using sampling protocols that establish beforehand at which site blood samples will be collected. Comparisons of mean $\mathrm{Hb}$ or anemia prevalence between regions or research studies that use different blood sampling protocols may be more problematic. If the difference in $\mathrm{Hb}$ between the sites is consistent, one could use a conversion factor to make venous and capillary samples comparable. Whether the difference in $\mathrm{Hb}$ is sufficiently consistent to apply a conversion factor is not well documented.

The portable photometer, Hemocue (Hemocue Inc., Mission Viejo, CA, USA) is used extensively in field studies for the estimation of $\mathrm{Hb}$. The instrument is reported to have high precision and accuracy in laboratory settings. ${ }^{8,9}$ In the field, some authors found adequate precision and accuracy ${ }^{3}$ while others did not. ${ }^{10}$ Chen and coworkers ${ }^{11}$ compared the accuracy and precision of the Hemocue to a reference method for the assessment of $\mathrm{Hb}$ in venous, arterial, and capillary blood. They found precision and accuracy were considerably reduced in samples of capillary origin. ${ }^{11}$
The extent to which the variability in $\mathrm{Hb}$ in capillary blood measured by Hemocue is due to biological variability, technical error, or instrument error has not been adequately documented.

Considerable intra-individual variability in capillary $\mathrm{Hb}$ has been reported over short time periods ${ }^{3,12}$ and between the right and left hand. ${ }^{3}$ Repeat capillary sampling has been suggested as a means of controlling for individual variability. Nonetheless, repeat samples are often not feasible in field settings and, in many cases, diagnoses continue to be made based on $\mathrm{Hb}$ from single capillary blood samples.

The study reported here was conducted as a validation of methods used in two large surveys and a longitudinal research project conducted by the Centro de Investigación en Nutrición y Salud, Instituto Nacional de Salud Pública (Center for Nutrition and Health Research at the National Institute of Public Health), in Mexico.* Our purpose was to assess the comparability of estimations of $\mathrm{Hb}$ as measured by Hemocue to those obtained by an automated spectrophotometer (Celldyn 1700, Abbott Diagnostics, Santa Clara, CA, USA), and to compare $\mathrm{Hb}$ in venous and capillary blood. We then examined the influence of method of $\mathrm{Hb}$ determination and sampling site on the estimated prevalence of anemia.

\section{Material and Methods}

The study took place in the Hospital del Niño Morelense (Morelos State Children's Hospital) in Cuernavaca, Morelos, Mexico, from February to May 2000, after re-

\footnotetext{
* Mexican National Nutrition Survey II. Impact evaluation of the Progresa Program in Mexico. The effect of multiple micronutrient supplementation during pregnancy on birth outcome and early prenatal growth (results forthcoming).
} 
ceiving clearance from the Committees for Human Subjects of the Children's Hospital and INSP. The hospital serves the low socio-economic population from the state of Morelos that do not have access to the National Social Security System. All hospital staff and all patients who were accompanied by at least one adult were invited to participate. The inclusion of hospital staff and patients was done in an attempt to ensure a large range of $\mathrm{Hb}$ concentrations. After a complete explanation of study procedures, the adult participant or the parent/guardian of the child participant was asked to sign informed consent. To allow for the analysis of data by age group, recruitment continued until the desired sample size was reached for adults and children.

Each participant was given a pamphlet of recommendations for the prevention of anemia and information about the importance of iron in the body. All anemic participants were given one months' supply of iron supplements (ferrous sulfate) free of cost and recommended to have a follow-up blood test at the end of the month. The dose and format (drops or pills) of supplemental iron was determined on the basis of age, sex, and physiological status.

Sample size was calculated based on the power to detect a correlation between the concentration of $\mathrm{Hb}$ measured by the Celldyn compared to the Hemocue, assuming that the correlation between the two measures is at least 0.5 (considered a large correlation). ${ }^{13}$ This calculation assumes that the variance in $\mathrm{Hb}$ is similar in capillary and venous blood assessed by each method and in children and adults. Allowing for an alpha error of 0.05 with a two-tailed test, a sample size of 60 provides power of 0.99 to detect a large correlation in $\mathrm{Hb}$.

\section{Blood collection and biochemical analysis}

Capillary and venous blood samples were collected from the right side of the body in alternating order. Both sample collection sites were previously cleaned with isopropyl alcohol. All analyses were conducted within 10 minutes of sample collection.

Venous samples were collected directly into Vacutainer tubes (Becton Dickinson, New Jersey, USA) containing potassium EDTA as anticoagulant. To avoid hemoconcentration, a tourniquet was placed on the arm at least $7 \mathrm{~cm}$ above the venipuncture site and left in place for less than 1 minute. The Vacutainer tube was inverted to ensure adequate mixture with the anticoagulant. A drop of blood was then collected by capillary action into the microcuvette specifically designed for the Hemocue system and $250 \mu \mathrm{l}$ of blood was poured into Microtainers (Becton Dickinson, New Jersey, USA) and analyzed directly in these tubes by Celldyn.

For the capillary blood sample, the fingertip was pierced using an automated lancet and the first drop of blood removed with a sterile cotton swab. Drops were collected directly into microtainers containing EDTA until the necessary volume of $250 \mu \mathrm{l}$ (approximately 4 drops, easily obtained from a normal finger stick sample) was reached and was then analyzed directly by Celldyn. Care was taken to avoid any pressure on the finger, which can result in hemodilution due to the inclusion of interstitial and intracellular fluids. Blood was also collected directly from the finger by capillary action into the Hemocue microcuvettes. The order of sample collection for the 2 systems was alternated.

The Hemocue system uses $10 \mu \mathrm{l}$ of blood collected into a special cuvette whose walls are lined with the dry reagents. The reagents react spontaneously with the blood sample resulting in erythrocyte membrane disintegration allowing for $\mathrm{Hb}$ release. Methemoglobin is formed by the conversion of iron from the ferrous to the ferric state, which combines with azide to form azide methemoglobin. ${ }^{14}$ Absorbance is read at 2 wavelengths as a means of controlling for sample turbidity. The apparatus converts the readings into $\mathrm{Hb}$ and displays the results digitally $(\mathrm{g} / \mathrm{dl})$. The concentration of $\mathrm{Hb}$ was recorded on the study questionnaire and double-checked by the laboratory technician. The Hemocue was calibrated daily using the calibration cuvette provided by the manufacturer.

In the automated system, Celldyn, erythrocyte membranes are also disintegrated to allow for the release of $\mathrm{Hb}$, which combines with potassium cyanide to form cyanomethemoglobin. ${ }^{15}$ All reagents are automatically measured and sample dilution occurs automatically, resulting in a high degree of precision. ${ }^{10,16}$ Absorbance is read automatically and converted to $\mathrm{Hb}$ $(\mathrm{g} / \mathrm{dl})$. Results are provided on a printed output, which were copied onto the study questionnaires and crosschecked with the printout. The Celldyn has been shown to have high precision and accuracy compared to the traditional cyanomethemoglobin method and other automated analyzers. ${ }^{17-19}$

Duplicate venous and capillary samples were collected at the time of sampling from the same sampling site on $20 \%$ of the subjects and assessed by both Celldyn and Hemocue methods. This was done to document reproducibility of $\mathrm{Hb}$ at each sampling site and by each analysis method.

For the purpose of this article, error associated with the analysis of $\mathrm{Hb}$ was divided into precision (sim- 
ilarity in repeat analyses), accuracy (values do not differ from a "gold standard"), and reliability (similarity of results over time and across measurement sites). ${ }^{3,20}$ All three may be influenced by instrument and technical error. Reliability is also influenced by biological variability.

$\mathrm{Hb}$ concentration in venous blood was compared to the concentration in capillary blood using each analysis method. Venous and capillary blood analyzed by Celldyn and Hemocue were compared to determine accuracy of the Hemocue in blood from each sample site. Finally, $\mathrm{Hb}$ from venous blood measured by the Celldyn was compared to capillary blood measured by the Hemocue. This comparison was considered to be of particular importance as it compares typically used field methods with what we considered a "gold standard" for the estimation of $\mathrm{Hb}$.

Concentrations were compared using the concordance correlation coefficient. ${ }^{21}$ This coefficient measures the strength of the relation between two estimates, as well as the deviation from the $45^{\circ}$ line through the origin (line of equity). The coefficient is considered a good method for comparing precision, reliability, and accuracy of test results. ${ }^{22}$ Although inadequate as statistical tests for this type of analysis, ${ }^{21-23}$ paired $t$-test for a difference in $\mathrm{Hb}$ for each comparison, the Pearson correlation coefficient, and the simple linear regression equations are also presented to allow for comparison with other photometer validation studies.

Anemia diagnosis was made using the age and sex specific cut-off points for $\mathrm{Hb}$ recommended by the World Health Organization. ${ }^{24}$ The cut-off point for adult males ( $>15$ years of age) and non-pregnant females was $<12.0 \mathrm{~g} / \mathrm{dl}$. A cut-off of $<11.0 \mathrm{~g} / \mathrm{dl}$ was used for male and female children from 1 to 6 years of age, and $<11.5 \mathrm{~g} / \mathrm{dl}$ was used for male and female children from 6-15 years of age. Although Cuernavaca is located at approximately $1500 \mathrm{~m}$ above sea level, cut-off points were not corrected for altitude. The difference in cut-off point at this altitude is very small, approximately $0.3 \mathrm{~g} / \mathrm{dl}^{25,26}$ and would have a minimal influence on prevalence estimates, sensitivity (Se) or specificity (Sp).

The diagnosis of anemia based on $\mathrm{Hb}$ in venous blood measured by Celldyn was considered true diagnosis. Anemia was diagnosed based on the capillary sample using Celldyn and the venous and capillary sample using Hemocue. The Se, Sp, positive predictive value (PPV), and negative predictive value (NPV) for the diagnosis of anemia by each of these methods were then estimated. There was no biologi$\mathrm{cal}$ reason to believe that the difference between $\mathrm{Hb}$ values estimated by the Hemocue and the Celldyn would differ by age. Nonetheless, we felt that an age difference may exist in the relationship between $\mathrm{Hb}$ in venous and capillary blood. Therefore, all analyses were conducted separately for adults and children.

\section{Results}

Blood samples were collected on a total of 72 children and 72 adults. Children ranged in age from 0.5 to 15 years and adults ranged from 17 to 73 years of age. Adult male participants $(n=20)$ were all hospital staff and adult female participants $(n=52)$ were hospital staff and family members accompanying patients in the outpatient clinic. Thirty-five male children and $37 \mathrm{fe}-$ male children, clinic outpatient patients, and family members accompanying them, participated in the study.

There were no differences between repeat measures for venous or capillary blood or for the Celldyn or the Hemocue. Estimates of between replicate variation (coefficient of variation) in $\mathrm{Hb}$ in venous blood were $4.4 \%$ and $4.3 \%$ for Celldyn and Hemocue, respectively. In capillary blood, the coefficients of variation were $4.5 \%$ and $3.9 \%$ for Celldyn and Hemocue, respectively.

On average, the $\mathrm{Hb}$ in capillary blood was higher than in venous blood (Table I). The difference ranged from $+0.17 \mathrm{~g} / \mathrm{dl}(\mathrm{p}=0.15)$ for samples from children measured by Hemocue, to $+0.59 \mathrm{~g} / \mathrm{dl}(p<0.0001)$ for samples from adults using the Hemocue. Despite this tendency, $\mathrm{Hb}$ was lower in capillary than in venous blood in $19 \%$ of adults and $21 \%$ of children. Among adults, concordance between $\mathrm{Hb}$ in capillary and venous blood was high, although lower for samples measured by Hemocue (0.88) compared to Celldyn (0.96). Concordance between $\mathrm{Hb}$ in capillary and venous blood among children was considerably lower and similar between methods of assessment $(0.82$ Celldyn; 0.81 Hemocue).

$\mathrm{Hb}$ concentration in both capillary and venous blood as measured by Hemocue was 0.29-0.68 g/ dl lower on average, than the concentration measured by Celldyn (Table II). Despite this tendency, the Hemocue measured a higher concentration in $6 \%$ of adults and $18 \%$ of children using venous blood. Concordance between analysis methods was high for both capillary and venous blood from adults and for venous blood collected from children (0.89-0.94). Concordance between analysis methods was considerably lower for capillary samples collected from children (0.79). To determine whether this difference existed across the entire range of $\mathrm{Hb}$, we plotted the difference between 
Table I

Hemoglobin Concentration (G/DL) in CAPILLARY bLOOd COMPAREd to Venous bloOd as MEASURED by Hemocue and Celldyn, and concordance between estimates. Cuernavaca, Mexico, 2000

Capillary blood* Venous blood Difference ${ }^{\ddagger} \quad$ Concordance correlation coefficient $\$$ Pearson correlation coefficient

Adults

\begin{tabular}{|c|c|c|c|c|c|}
\hline Celldyn & $14.1 \pm 2.1(8.7-17.5)^{\#}$ & $13.6 \pm 2.1 \quad(8.7-16.9)$ & $+0.42 \pm 0.45^{\neq}$ & $0.96 \quad(0.94-0.98)$ & 0.98 \\
\hline Hemocue & $13.8 \pm 2.0 \quad(9.5-16.9)$ & $13.1 \pm 1.9 \quad(8.2-17.2)$ & $+0.59 \pm 0.74^{\neq}$ & $0.88 \quad(0.84-0.94)$ & 0.93 \\
\hline \multicolumn{6}{|l|}{ Children } \\
\hline Celldyn & $12.5 \pm 1.6(8.8-15.2)^{\star}$ & $12.0 \pm 1.6 \quad(8.2-14.7)$ & $+0.55 \pm 0.79 \neq$ & $0.82(0.74-0.90)$ & 0.87 \\
\hline Hemocue & $11.8 \pm 1.8 \quad(7.4-15.2)$ & $11.6 \pm 1.4 \quad(8.4-13.8)$ & $+0.17 \pm 0.98$ & $0.81 \quad(0.73-0.88)$ & 0.83 \\
\hline
\end{tabular}

* Mean \pm standard deviation (range)

₹ Mean of difference \pm standard deviation of the difference (capillary - venous); statistical testing based on paired t-test for difference in hemoglobin concentration in capillary and venous blood

\$ $95 \%$ confidence interval in parentheses

\# 2 observations missing $(n=70)$

$\& 6$ observations missing $(n=68)$

$\neq p<0.0001$

Table II

Difference in hemoglobin concentration (G/DL) as estimated by Hemocue and Celldyn in venous and Capillary blood, and concordance between estimates. Cuernavaca, Mexico, 2000

Difference $\left(g / d \|^{*}\right) \quad p$-value $e^{\ddagger} \quad$ Concordance correlation coefficient ${ }^{\S} \quad$ Pearson correlation coefficient

Adults

\begin{tabular}{lcccc} 
Hemocue - Celldyn (venous blood) & $-0.47 \pm 0.53(-1.7,1.6)$ & $<0.0001$ & $0.94(0.91-0.97)$ & 0.97 \\
\hline Hemocue - Celldyn (capillary blood) & $-0.29 \pm 0.78(-2.9,2.2)$ & $<0.01$ & $0.92(0.88-0.96)$ & 0.93 \\
\hline Hemocue capillary - Celldyn venous & $0.12 \pm 0.87(-2.8,2.9)$ & 0.25 & $0.91(0.87-0.95)$ & 0.91
\end{tabular}

Children

\begin{tabular}{lcccc} 
Hemocue - Celldyn $₫$ (venous blood) & $-0.31 \pm 0.63(-2.1,1.8)$ & $<0.0001$ & $0.89(0.84-0.94)$ & 0.91 \\
\hline Hemocue- Celldyn (capillary blood) & $-0.68 \pm 0.88(-3.2,1.2)$ & $<0.0001$ & $0.79(0.70-0.88)$ & 0.86 \\
\hline Hemocue capillary - Celldyn venous & $-0.14 \pm 1.05(-2.8,1.8)$ & 0.25 & $0.79(0.71-0.88)$ & 0.80
\end{tabular}

* Mean of the difference \pm standard deviation of the difference (minimum, maximum)

₹ From paired t-test

\& $95 \%$ confidence interval in parentheses

* 2 observations missing $(n=70)$

\& 6 observations missing $(n=68)$

venous $\mathrm{Hb}$ estimated by Celldyn and Hemocue against the mean of the estimates (Figure 1) for adults (Panel A) and children (Panel B). Due to the limitations of regression analysis to reflect agreement between measures, this has been suggested as a more adequate means of graphically depicting comparisons between analysis methods. ${ }^{23}$ We show only data for venous blood due to potential bias in capillary samples col- lected from children. Nonetheless, the pattern in capillary blood is similar to that shown in Figure 1.

A graphic presentation of the raw data showing the simple least squares regression line suggests that among adults (Figure 2,) (Panel A), the assessment of $\mathrm{Hb}$ in capillary blood using Hemocue adequately represents the concentration in venous blood assessed by Celldyn. Among children, $\mathrm{Hb}$ in capillary blood as- 


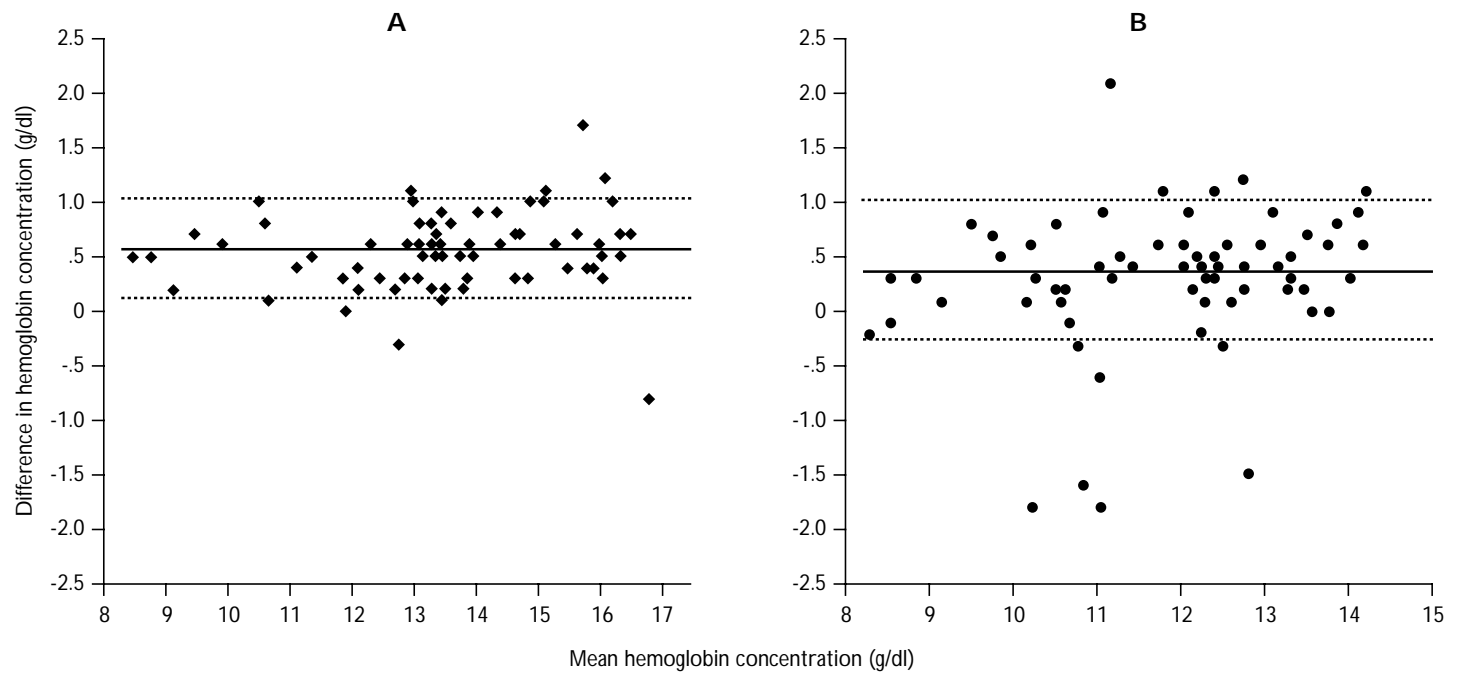

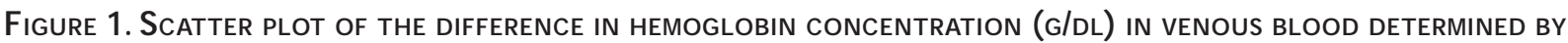
Celldyn minus the concentration in venous blood determined by Hemocue for adults (A) and children (B) BY THE MEAN OF THE ESTIMATES. SOLID LINE REPRESENTS MEAN DIFFERENCE, DASHEd LINES REPRESENTS \pm 1 STANDARD deviation. Cuernavaca, Mexico, 2000

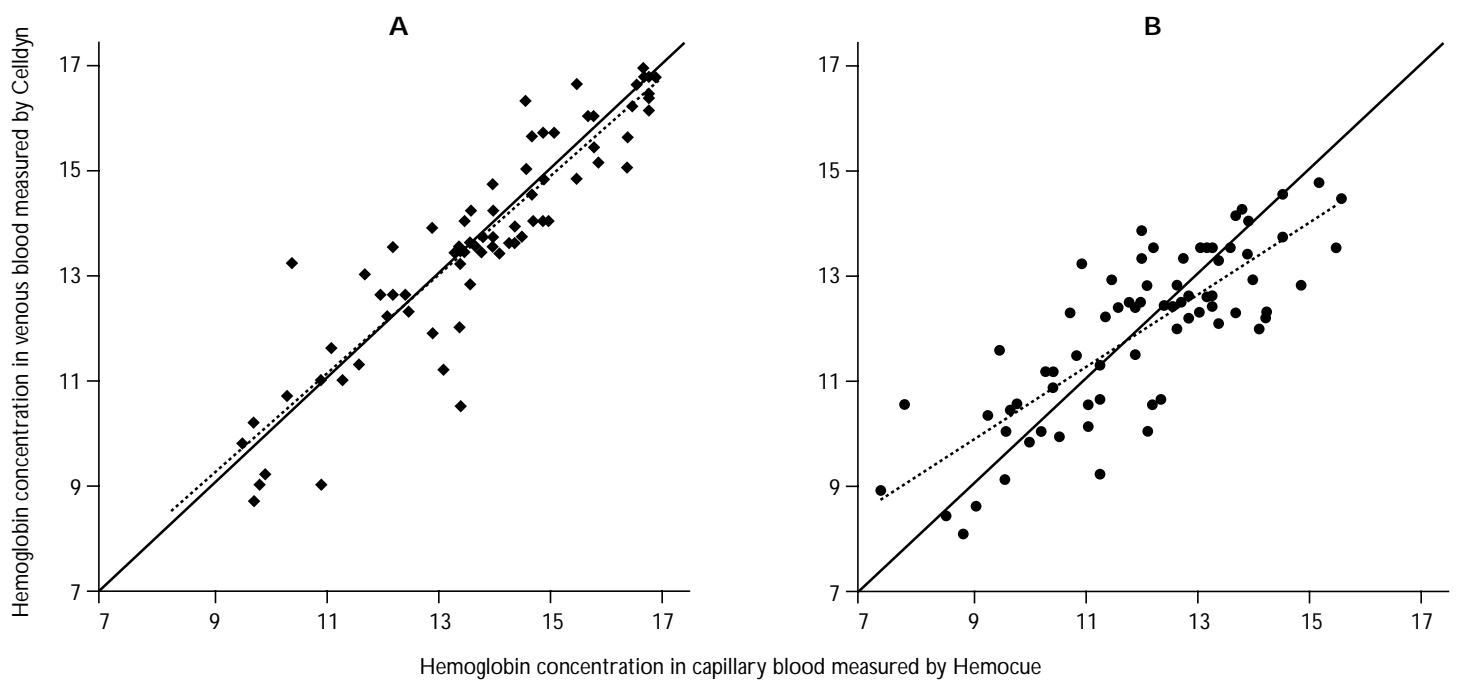

Figure 2. Scatter plot of hemoglobin concentration (G/DL) in venous blood determined by Celldyn and

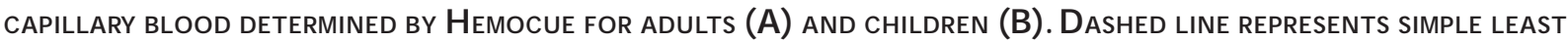
squares regression line, solid line represents line of equity. Cuernavaca, MeXico, 2000

sessed by Hemocue appears to underestimate the concentration as assessed by Celldyn in venous blood below approximately $12.5 \mathrm{~g} / \mathrm{dl}$ (Figure 2,) (Panel B) and to overstimate at higher values.
Among adults, $\mathrm{Hb}$ from capillary blood using the Hemocue had a low Se $(<80 \%)$ for identifying anemia (Table III), as did $\mathrm{Hb}$ estimated from capillary blood using the Celldyn in children. Se for all other methods 
Table III

\begin{abstract}
Sensitivity, SPECIFICITY, POSITIVE PRedictive VALUe, AND negative PRedictive VALUe

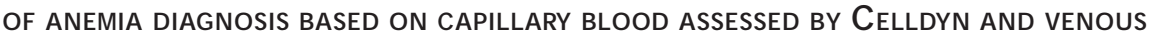
and Capillary blood assessed by Hemocue. Cuernavaca, Mexico, 2000
\end{abstract}

\begin{tabular}{|c|c|c|c|c|c|}
\hline Method & Prevalence $(\%)$ & Sensitivity (\%) & Specificity (\%) & Positive predictive value (\%) & Negative predictive value (\%) \\
\hline \multicolumn{6}{|l|}{ Adults ( $\geq 17$ years) } \\
\hline "True" diagnosis & 19.4 & - & - & - & - \\
\hline \multicolumn{6}{|l|}{ (Celldyn, venous blood) } \\
\hline Celldyn, capillary blood & 16.7 & 86 & 100 & 100 & 97 \\
\hline Hemocue, venous blood & 19.4 & 86 & 97 & 86 & 97 \\
\hline Hemocue, capillary blood & 18.1 & 79 & 97 & 85 & 95 \\
\hline \multicolumn{6}{|l|}{ Children (0.5 - 15 years) } \\
\hline "True" diagnosis & 41.9 & - & - & - & - \\
\hline \multicolumn{6}{|l|}{ (Celldyn, venous blood) } \\
\hline Celldyn, capillary blood & 39.2 & 77 & 88 & 83 & 84 \\
\hline Hemocue, venous blood & 40.5 & 87 & 93 & 90 & 91 \\
\hline Hemocue, capillary blood & 39.2 & 84 & 93 & 90 & 89 \\
\hline
\end{tabular}

and $\mathrm{Sp}$ for all methods of diagnosis were adequate $(>80 \%)$. PPV and NPV were adequate $(>80 \%)$ for both methods of analysis at each sampling location.

As a means of determining whether the use of an adjustment factor for capillary blood would improve the Se and Sp of capillary blood for anemia diagnosis, we subtracted the mean difference in $\mathrm{Hb}$ between capillary and venous blood measured by Celldyn $(0.5$ $\mathrm{g} / \mathrm{dl}$ ) from capillary $\mathrm{Hb}$. For both children and adults, concordance between venous and capillary samples measured by Celldyn improved compared to unadjusted capillary values ( 0.98 adults, 0.87 children). Prevalence estimations, Se, Sp, PPV, and NPV were unchanged for adults and improved for children (prevalence 41.9\%; Se 84\%; Sp 88\%; PPV 84\%; NPV 88\%). In contrast, concordance between the venous sample measured by Celldyn and the capillary sample measured by Hemocue was lower than for the unadjusted values (0.90 adults, 0.74 children). Prevalence estimates were considerably higher (adults $26.4 \%$; children $46.0 \%$ ) reflected in unchanged Se for adults and higher Se for children (90\%) but reduced Sp for adults (97\%) and children $(86 \%)$.

\section{Discussion}

In many rural regions of developing countries where the prevalence of anemia may be particularly high and resources are limited, the collection of venous blood samples is often unacceptable and analysis of fresh blood by standard laboratory methods, unfeasible. The estimation of $\mathrm{Hb}$ in capillary blood using portable photometers permits the collection of information that may otherwise be inaccessible. The Pan American Health Organization (PAHO) has identified the fundamental role of rapid, economical surveys as opposed to sophisticated research projects as a means of collecting baseline information on iron status of populations. ${ }^{27}$ Nonetheless, the extent to which variability in $\mathrm{Hb}$ in and between venous and capillary blood and methods of analysis, influences the precision, validity, and reliability of the estimates and anemia prevalence estimates, has not been adequately examined.

We found that among both children and adults, $\mathrm{Hb}$ in capillary blood was on average, $0.5 \mathrm{~g} / \mathrm{dl}$ higher than in venous blood. This difference likely reflects biological variability between $\mathrm{Hb}$ at these sites, and thus may influence reliability of $\mathrm{Hb}$ estimates. Inadequate capillary sample collection technique may influence $\mathrm{Hb}$ by hemodilution, but would not explain hemoconcentration. If sample collection technique had a major influence on $\mathrm{Hb}$, one may expect greater intra- and inter-individual variability in capillary blood samples. This was not observed in the present study, as demonstrated by the relatively similar standard deviation between measurement sites.

The reasons why there was a smaller difference between venous and capillary blood assessed by Hemocue only on samples collected from children (Table 
I) are not entirely clear. Because the difference between $\mathrm{Hb}$ in venous and capillary blood from children assessed by Celldyn was similar to that found in adults, we believe that capillary sample collection directly into Hemocue microcuvettes may have influenced capillary $\mathrm{Hb}$. Capillary samples are more difficult to collect from small children and if the Hemocue cuvettes were filled inadequately or inadequate sampling technique was used, a lower $\mathrm{Hb}$ may result. This would also explain the larger difference between Hemocue and Celldyn in capillary blood for children (Table II). We find these results surprising considering that our staff was highly trained and considerable effort was made to ensure adequate laboratory techniques and emphasize the critical role of sample collection techniques used on children.

The accuracy of $\mathrm{Hb}$ estimated by Hemocue in laboratory settings is usually high. ${ }^{3,8,9}$ The systematically lower mean $\mathrm{Hb}$ measured by Hemocue (Figure 1) in this study may be related to sample collection technique or equipment error. Because the difference is similar in capillary and venous blood and in both age groups, it is unlikely a result of sample collection or analysis technique and may be related to equipment. It appears that our Hemocue tended to underestimate $\mathrm{Hb}$ and this tendency increased with increasing $\mathrm{Hb}$. Alternately, our Celldyn may have underestimated $\mathrm{Hb}$, with greater underestimation at lower $\mathrm{Hb}$. The Hemocue used in this study was calibrated on a daily basis and error was within the limits specified by the manufacturer. The hospital laboratory undergoes periodic external evaluation to ensure high precision and accuracy of all hematological evaluations. Further study, including calibration of the Hemocue over the entire range of expected $\mathrm{Hb}$ concentrations is required to determine the source of these differences.

No precise method of calculating sample size for validation studies exists and we recognize that the calculation based on finding a correlation between methods is not entirely adequate. We conducted power analyses using the JMP program (SAS Institute Inc., Cary, NC). This program tests whether the slope of the regression between two sets of measurements differs from 1 and whether the intercept is 0 , thus providing results similar to those of the concordance correlation coefficient. A sample of 72 provides power of approximately $0.82-0.93$ to detect a difference in slope of 0.2 between the various comparisons made in the present study. Thus, we conclude that our sample size was adequate to evaluate agreement between $\mathrm{Hb}$ assessed by different methods in capillary and venous blood.
According to the present study, $\mathrm{Hb}$ measured in capillary blood could result in a false negative anemia diagnosis. Nonetheless, the difference in prevalence estimates based on $\mathrm{Hb}$ in venous blood measured by Celldyn and capillary blood assessed by Hemocue was not large $(<2 \%)$ and our results confirm previous studies $^{3}$ suggesting that the use of $\mathrm{Hb}$ estimated from capillary blood using Hemocue is adequate for anemia prevalence estimates in populations. It is important to note that highly trained laboratory personnel collected and analyzed all samples under ideal conditions (e.g. limited time between sample collection and analysis). Although this is not the norm for most field studies, similar conditions can be ensured in a field setting using strict protocols, adequate training, and quality control.

The use of a conversion factor from capillary to venous blood improved concordance, Se, and Sp when the capillary sample was assessed by Celldyn. Although this suggests improved ability to correctly diagnose anemia using capillary blood, most field studies are dependent on portable photometer such as Hemocue. For capillary samples measured by Hemocue, concordance was better for the unadjusted values. Although we do not recommend the use of the adjustment factor at this time, further research should be conducted to determine its usefulness, particularly for adults.

The present study is one of the few that has attempted to identify sources of error related to the estimation of $\mathrm{Hb}$ in venous and capillary blood and to determine the extent to which blood sampling site and method of assessment influence anemia prevalence estimates. We found high precision for the estimation of $\mathrm{Hb}$ in venous and capillary blood using both Hemocue and Celldyn. The accuracy of the Hemocue was poorer than that reported in other studies, the reasons for which require further investigation. The use of a single capillary blood sample measured by Hemocue resulted in an adequate ability to identify those who truly were not anemic (high Sp). The ability to correctly diagnose anemia among the truly anemic (Se) was lower. Methods to ensure high precision and accuracy, including adequate sample collection technique, particularly for children and strict equipment calibration should be carefully planned and followed in all research and programs that estimate $\mathrm{Hb}$ in capillary blood. Clear reporting of methods may help to avoid inappropriate comparisons between measurement sites where the $\mathrm{Hb}$ may be influenced by biological variability. 


\section{References}

1. DeMaeyer E,Adiels-Tegman M.The prevalence of anemia in the world. World Health Stat Q 1985;38:302-316.

2.Administrative Committee on Coordination, Sub-C ommittee on N utrition. (ACC/SCN) Third report on the world nutrition situation. Ginebra: United N ations, 1997.

3. Morris S, Ruel M, Cohen R, D ewey K, Brière BDL, Hassan M. Precision, accuracy, and reliability of hemoglobin assessment with use of capillary blood. Am J C lin N utr 1999;69:1243-1248.

4. Daae LN , Halvorsen S, Maticen PM, Mironska K.A comparison between haematological parameters in 'capillary' and venous blood from healthy adults. Scand J C lin Lab Invest 1988;48:723-726.

5. Hutler M, Beneke R, Boning D. D etermination of circulating hemoglo bin mass and related quantities by using capillary blood. Med Sci Sports Exerc 2000;32:1024-1027

6. Moe PJ. Hemoglobin, hematocrit and red blood cell count in "capillary" (skin-prick) blood compared to venous blood in children. Acta Paediatr Scand 1970;59:49-51.

7.Thomas W J, CollinsTM. Comparison of venipuncture blood counts with microcapillary measurements in screening for anemia in one-year-old infants. J Pediatr 1982;101:32-35.

8. Bridges $N$, Parvin RM, van Assendelft OW. Evaluation of a new system for hemoglobin measurement. Am C lin Products Rev 1987;6:22-25.

9. Cohen A, Seidl-Friedman J. HemoC ue system for hemoglobin measurement. Am J Clin Pathol 1988;90: 302-305.

10. N eville R. Evaluation of portable haemoglobinometer in general practice. Br Med J 1987;294:1263-1265.

11. Chen P, Short T, Leung D, O h T. A clinical evaluation of the Hemocue haemoglo binometer using capillary, venous, and arterial samples. A naesth Intens Care 1992;20:497-503.

12. Statlande BE,W inkel P, Harris SC, Burdsall MJ, Saunders AM. Evaluation of biological sources of variation of leukocyte counts and other hematologic quantities using very precise automated analyzers. Am J C lin Pathol 1977;69:48-54
13. Cohen J. Statistical power analysis for the behavioral sciences. Second edition. $N$ ueva Jersey (N J): Hillsdale Publishers, 1988.

14. von Schenck H, Falkensson M, Lundberg B. Evaluation of "HemoC ue", a new device for determining hemoglobin. Clin Chem 1986;32:526-529. 15. Drabkin DL, Austin JH. Spectrophotometric studies: Spectrophotometric constants for common hemoglobin derivatives in human, dog and rabbit blood. J Biol Chem 1932;98:719-733.

16. Bigbee J,W inter B. Reliability and validity testing of the whole-blood hemoglobinometer. Public Health N urs 1990;7:40-44.

17. Sandberg S, Thue G, Christensen HG, Lund PK, Rynning M. Performance of cell counters in primary health care. Scand J Prim Health Care 1991;9:129-133.

18. Petani S,Topic E,Turcic G, Daschner M. C linical evaluation of the C ellDyn 1700C S blood counter. Clin Chem 1997;43:1085-1088.

19. Sachse C, Henkel E.An evaluation of the CELL-DYN 1700 haematology analyzer:Automated cell counting and three-part leucocyte differentiation. Clin Lab Haematol 1996;18:171-180.

20. Marks GC, H abicht JP, Mueller W H. Reliability, dependability, and precision of anthropometric measurements. The Second $\mathrm{N}$ ational $\mathrm{Health}$ and N utrition Survey 1976-1980. Am J Epidemiol 1989;130:578-587.

21. Lin L.A concordance correlation coefficient to evaluate reproducibility. Biometrics 1989;45:255-268.

22. Lin L. Assay validation using the concordance correlation coefficient. Biometrics 1992:48:599-604

23. Bland JM,AtIman DG. Statistical methods for assessing agreement between two methods of clinical measurement. Lancet 1986;8176:307-310. 24. Gillespie S, Johnston JL. Expert consultation on anemia determinants and interventions. 0 ttawa: Micronutrients Initiatives, 1998.

25. Cohen JH, Haas JD. Hemoglo bin correction factors for estimating the prevalence of iron deficiency anemia in pregnant women residing at high altitudes in Bolivia. Rev Panam Salud Publica 1999;6:392-399.

26. Ruiz-Argüelles $G$ J, Llorente-Peters A. Predictive equations for normal red cell values at altitudes from sea level to 2,670 meters. Rev Invest C lin Mex 1981;33:191-193.

27. FreireW B. Strategies of the Pan A merican $\mathrm{H}$ ealth 0 rganization for the control of iron deficiency in Latin America. N utr Rev 1997;55:183-188. 